\title{
Wing-Propeller Interaction
}

\author{
Nikola Zizkovsky ${ }^{1, *}$, and Jan Klesa ${ }^{1}$ \\ ${ }^{1}$ Department of Aerospace Engineering, Czech Technical University in Prague, 12135 Praha 2, \\ Czech Republic
}

\begin{abstract}
Paper describes the effect of the distributed electric propulsion system (DEP) on the aerodynamic characteristics of the airplane wing. Using CFD simulation is described the influence of the wake of the propeller on the wing for various ratios of the propeller diameter to the wing chord. Unlike the normal case of wing-propeller interaction, periodic boundary conditions are used, i.e. a rectangular wing with infinite span with propellers installed periodically its span is considered. A wind tunnel experiment will be used to verify the calculations. Propeller thrust is set to compensate for airplane drag in horizontal flight, i.e. equal to the wing segment drag, which is increased by the corresponding part of the expected drag of other parts of the airplane. The increase of the drag was determined by the aerodynamic design of a generic airplane with DEP. The benefit of the work are the input data usable for the conceptual design of the airplane wing with DEP.
\end{abstract}

\section{Introduction}

Distributed electric propulsion (DEP) represents modern direction of research. The main idea is to use accelerated air flow behind propellers for lift increase during take-off and landing. This leads to the smaller wing area and thus to the higher efficiency in cruise. However, aircraft design and optimization become more complex and bring new challenges.

Standard DEP concepts use many small propellers in front of wing leading edge [1]. This is used e.g. at X-57 Maxwell experimental aircraft, see [2] or EcoPulse project, see [3]. Lithium project, see [4], should have also vertical take off and landing characteristics (VTOL) and uses many small fans on the wing upper surface near the trailing edge. Especially NASA has done research in the field of DEP physics and the interaction of the wing and propeller (see [5-9]).

Main motivation for this paper is to bring more information about the interaction of wing and propeller in the typical DEP configuration, especially understanding of wing propeller interactions. It should help to answer the question how to size up propellers with the respect to wing chord and how big the propeller distance should be in order to reach maximum performance of the propulsion system. Results can be used for the design and optimization of the DEP aircraft.

*Corresponding author: nikola.zizkovsky@ffs.cvut.cz 


\section{Problem definitions}

The influence of propeller slipstream on the aerodynamic characteristics of the wing, especially lift, is studied. The propeller is designed by Larrabee's method (see [10]). Input parameters can be found in Table 1. Propeller diameter remains the same all cases. TsAGI B airfoil is used for the wing. Various combinations of wing chard and various distances between propellers are used. Periodic boundary conditions are used, so only one wing segment is analysed (see Fig. 1). The aim is to compute wing lift and drag for every configuration. Following wing geometries are used:

- Propeller distance 250 and $600 \mathrm{~mm}$

- Wing chord 100, 200 and $400 \mathrm{~mm}$

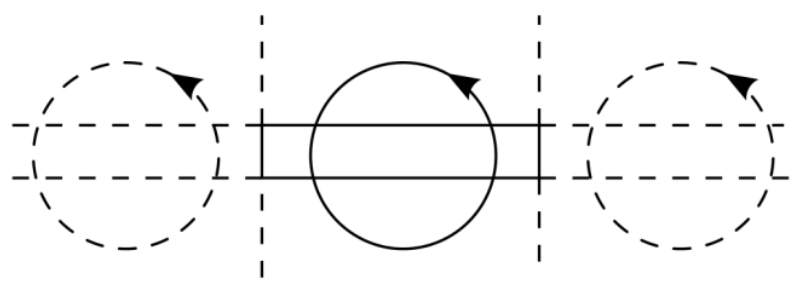

Fig. 1. Schematic front view on the wing, periodic boundary condition is used.

Table 1. Input parameters for propeller design.

\begin{tabular}{|c|c|}
\hline Number of blades & 2 \\
\hline Diameter $[\mathrm{m}]$ & 0.2 \\
\hline Flight velocity $\left[\mathrm{m} \cdot \mathrm{s}^{-1}\right]$ & 20 \\
\hline Propeller RPM & 17,400 \\
\hline Consumed power $[\mathrm{W}]$ & 500 \\
\hline
\end{tabular}

\section{Methods}

\subsection{CFD simulation}

Computational Fluid Dynamics (CFD) simulation is used for wing-propeller interaction analysis. OpenFoam solver is used with RANS Spallart-Almaras turbulence model. The solver is steady, segregated and compressible. No wall functions are used. Propeller is modelled by the means of actuator disc with customized interpretation, see [11], where radial distribution of twist and chord is used. As input data for propeller sections the aerodynamics characteristics were calculated in JavaFoil. Calculated velocities in front of and behind the actuator disc and also thrust of propeller is within $2 \%$ tolerance compared to values obtained from design method.

Castellated computational mesh is used with prismatic layers near wall boundary condition.

On flat sides of cylindrical computational domain is used periodic boundary condition. Usage of symmetrical boundary condition on cylinder bottoms was tested at one angle of attack. 
Wind tunnel tests will be carried out for the verification of the experiments (see Fig. 2) at small wind tunnel for chord $200 \mathrm{~mm}$ only.

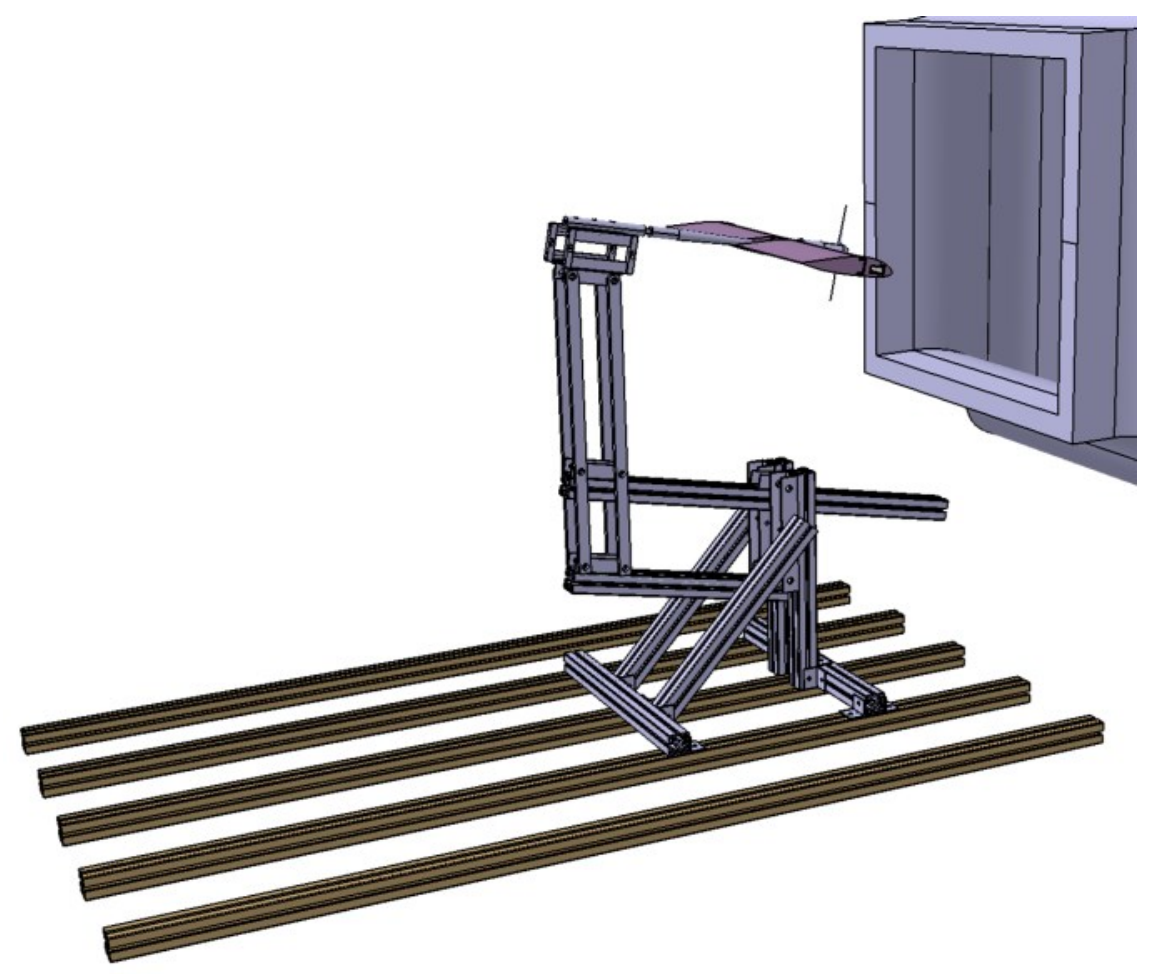

Fig. 2. Wind tunnel testing experimental setup

\subsection{Analysis of results}

Transformation of lift and drag coefficients is used so that results for different wing geometries can be compared. The equivalent aerodynamic coefficients are determined as standard coefficient for given conditions multiplied by ratio of actual and reference wing area. Reynolds number range is from 138000 for $100 \mathrm{~mm}$ chord to 552000 for $400 \mathrm{~mm}$ chord.

\section{Results}

Flow fields for various configurations are presented in Figs. 3 to 10. Case without propeller in Fig. 3 is shown for comparison purposes. Polar graphs (i.e. dependence of equivalent lift coefficient on the equivalent drag coefficient) for wingspan to propeller radius equal to 2.5 and 6 are presented in Figs. 10 and 11 .

From figures 4 and 6 to 8 is visible influence of wing, which splits air flow to two separate flows which starts to interact behind wing. Air flow twist behind rotor is limited due to propeller configuration, especially advance ratio, which limits final efficiency. 


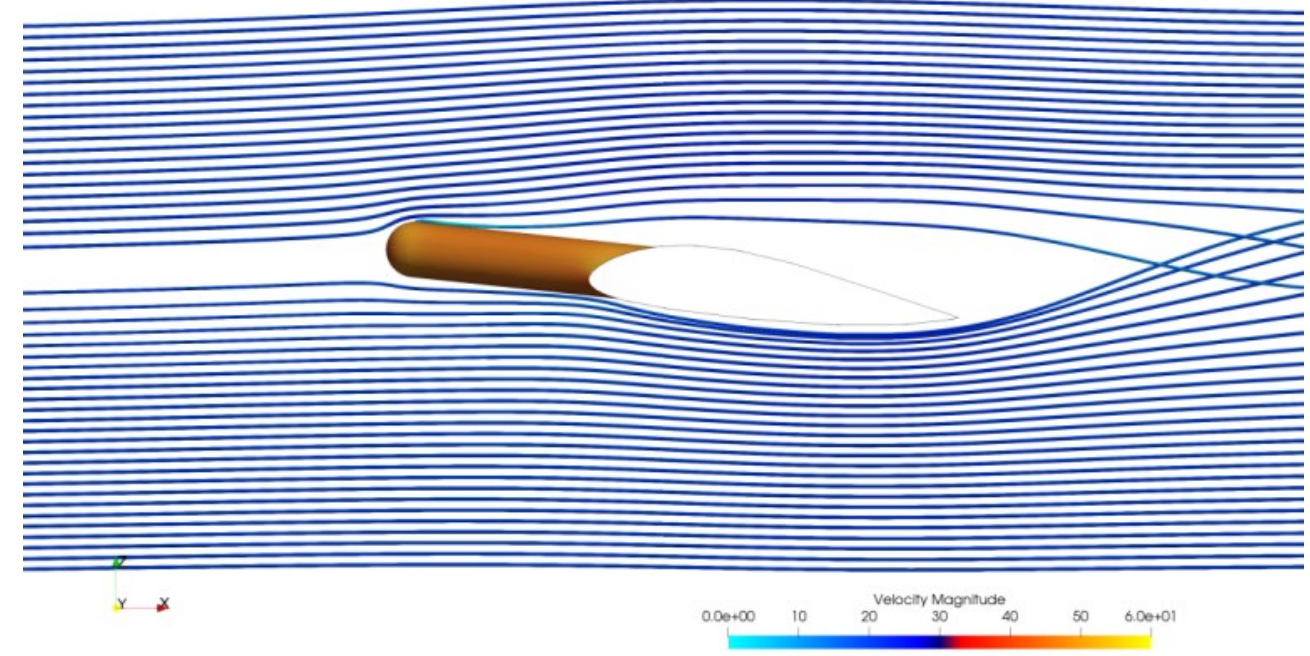

Fig. 3. Streamlines for the configuration with $200 \mathrm{~mm}$ chord and $600 \mathrm{~mm}$ wingspan without propeller.

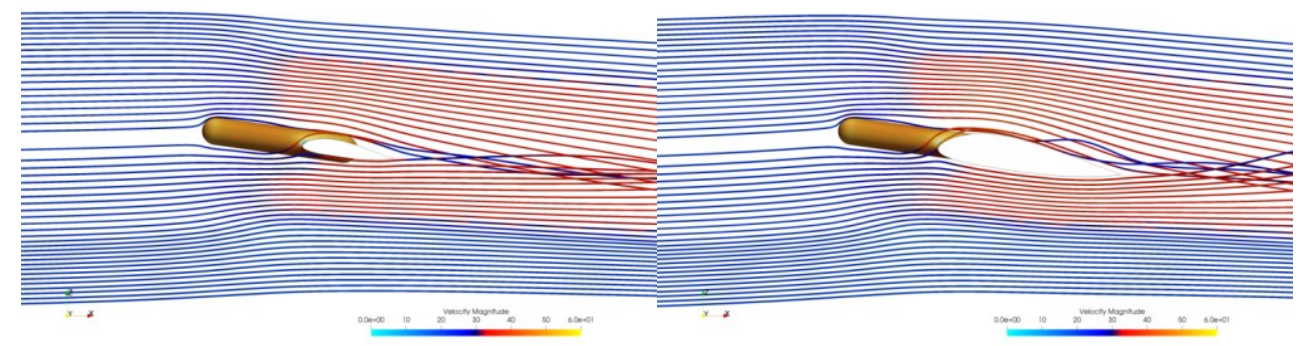

Fig. 4. Streamlines for the configuration with 100 and $200 \mathrm{~mm}$ chord with $600 \mathrm{~mm}$ wingspan.
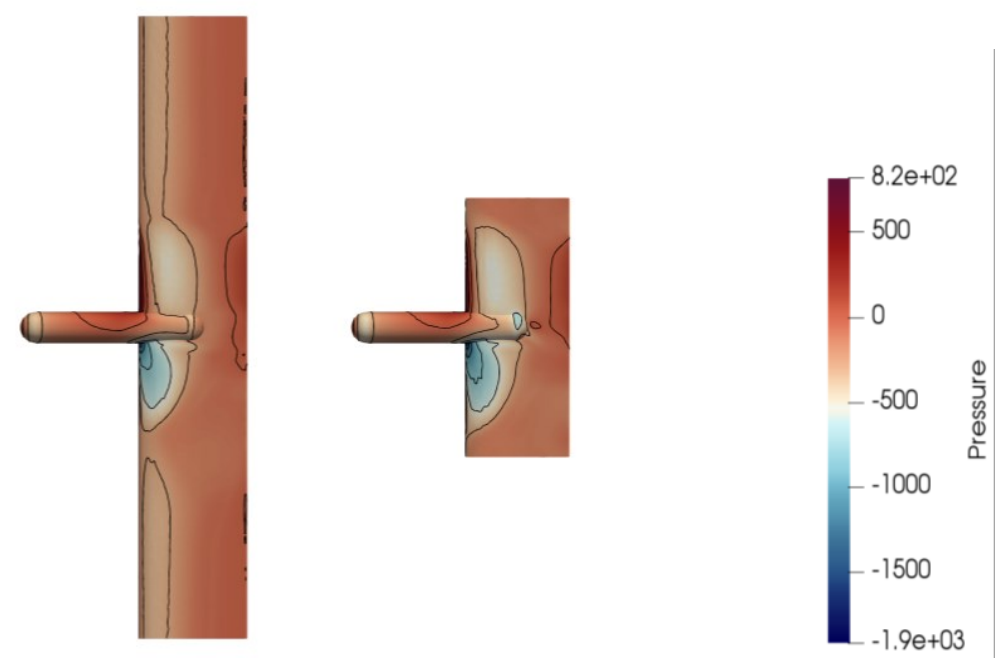

Fig. 5. Surface static pressure for $100 \mathrm{~mm}$ chord with $600 \mathrm{~mm}$ and $250 \mathrm{~mm}$ wingspan. 


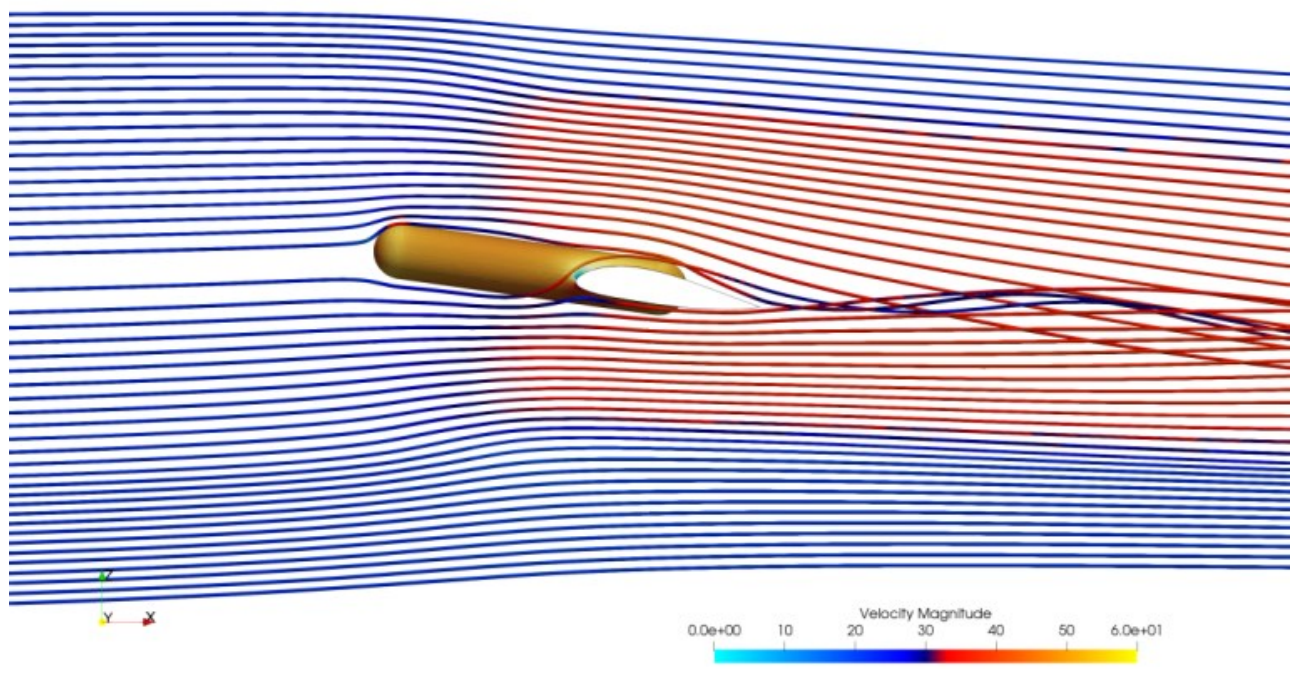

Fig. 6. Streamlines for the configuration with $100 \mathrm{~mm}$ chord and $250 \mathrm{~mm}$ wingspan.

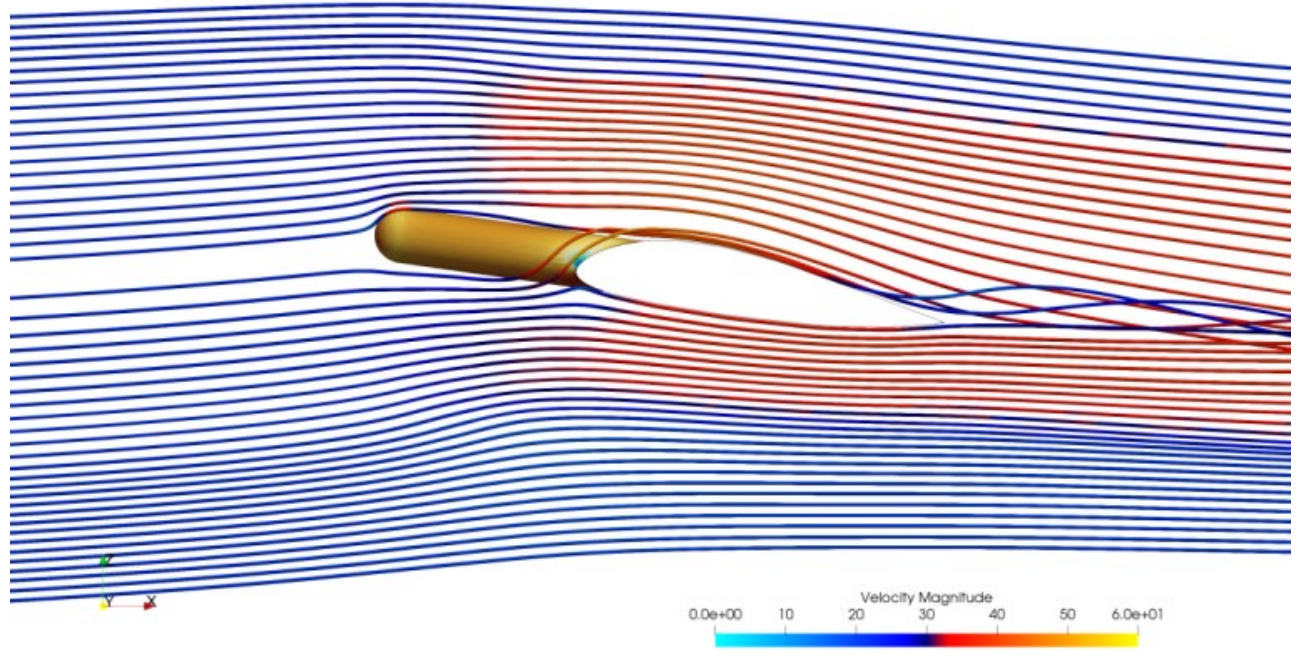

Fig. 7. Streamlines for the configuration with $200 \mathrm{~mm}$ chord and $250 \mathrm{~mm}$ wingspan. 


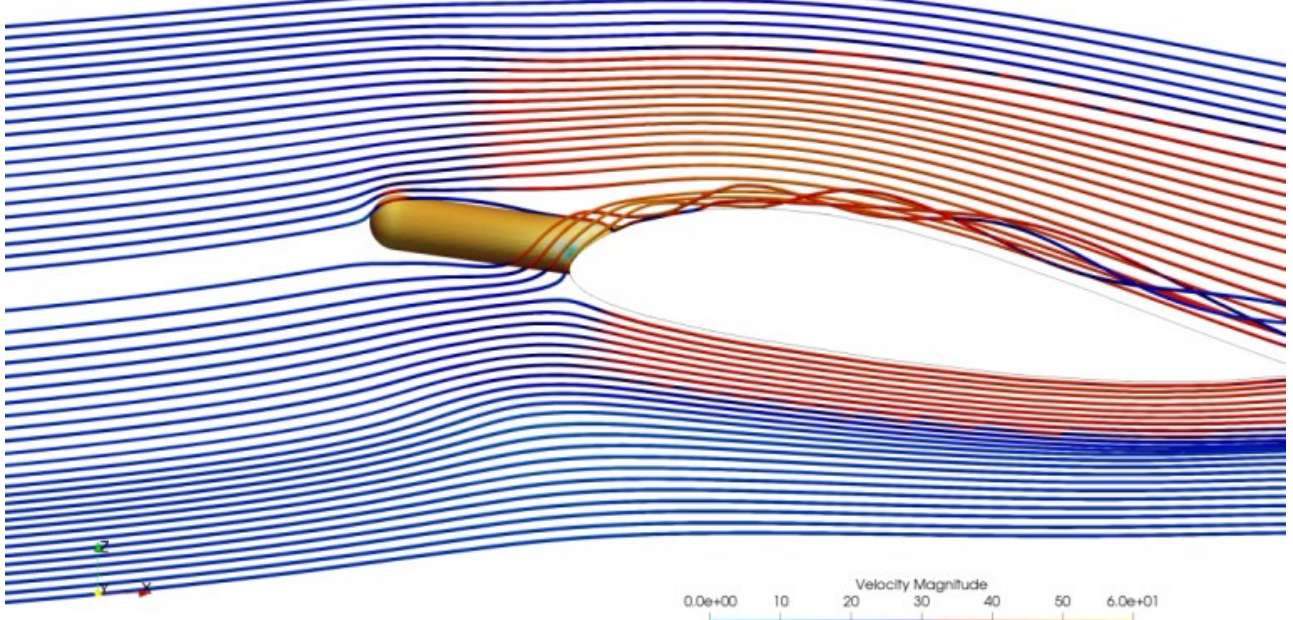

Fig. 8. Streamlines for the configuration with $400 \mathrm{~mm}$ chord and $250 \mathrm{~mm}$ wingspan.

The axial velocity magnitude is shown on Fig. 9, which corresponds to variant with 600 $\mathrm{mm}$ wingspan and $100 \mathrm{~mm}$ chord. Section plane is located in wake, $100 \mathrm{~mm}$ behind wing. Figure 9 shows the rotational effect behind propeller.

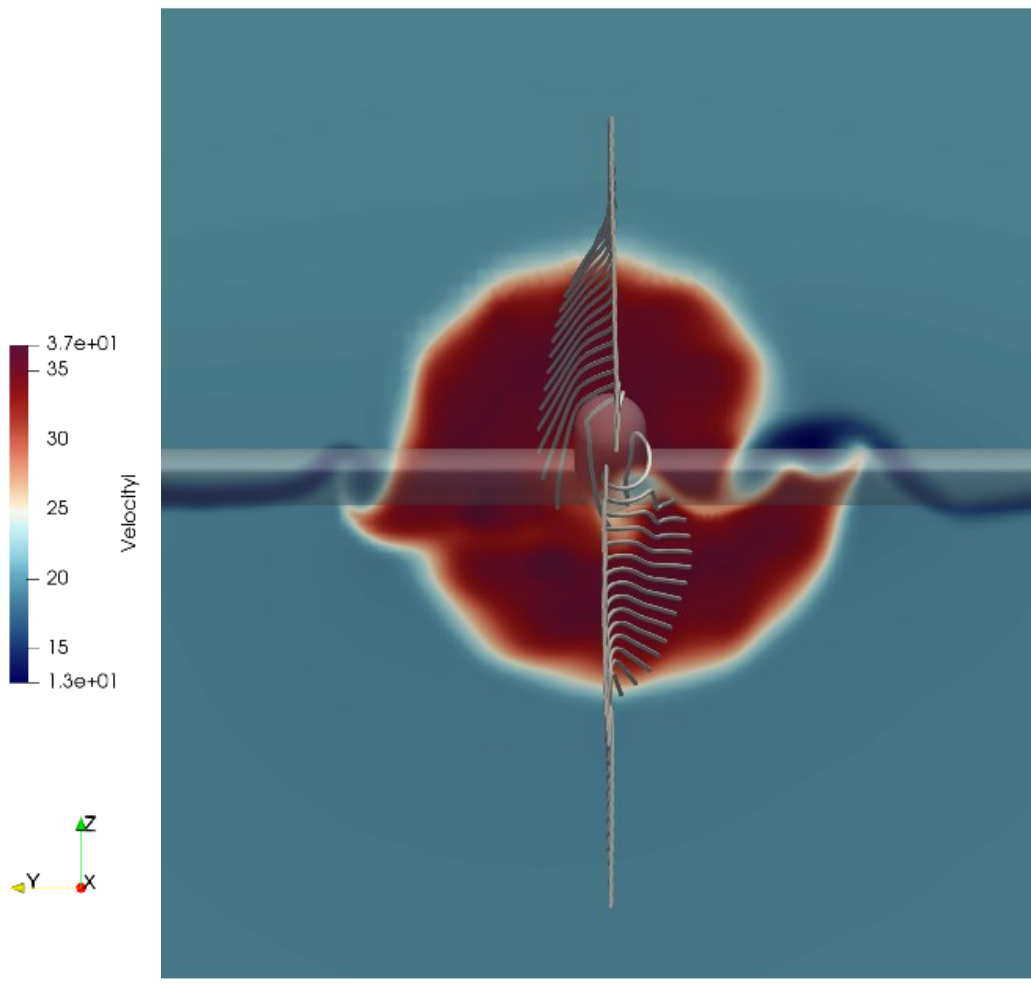

Fig. 9. Streamlines and axial velocity filed in distance $100 \mathrm{~mm}$ behind TE for $100 \mathrm{~mm}$ chord and $600 \mathrm{~mm}$ wingspan - frontal view. 


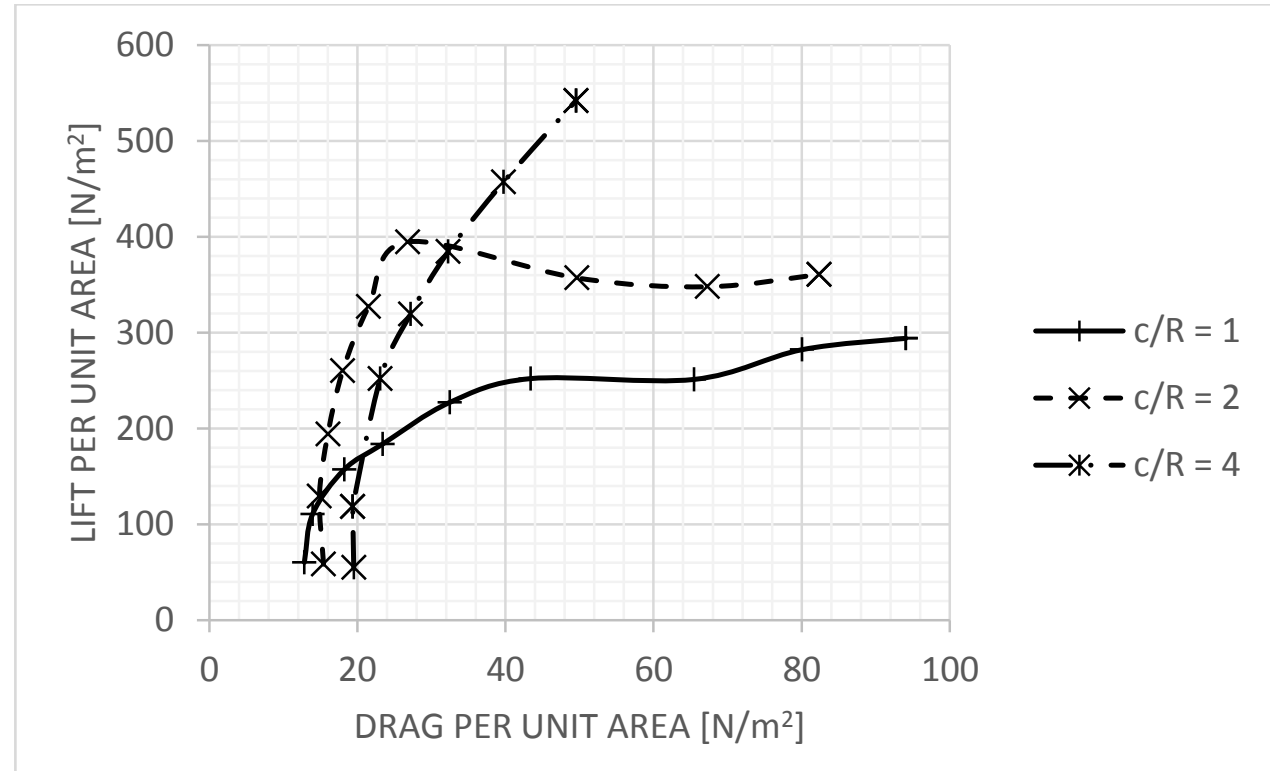

Fig. 10. Unit aerodynamic forces graphs for various ratios of wing cord to propeller radius for wingspan to propeller radius equal to 2.5 .

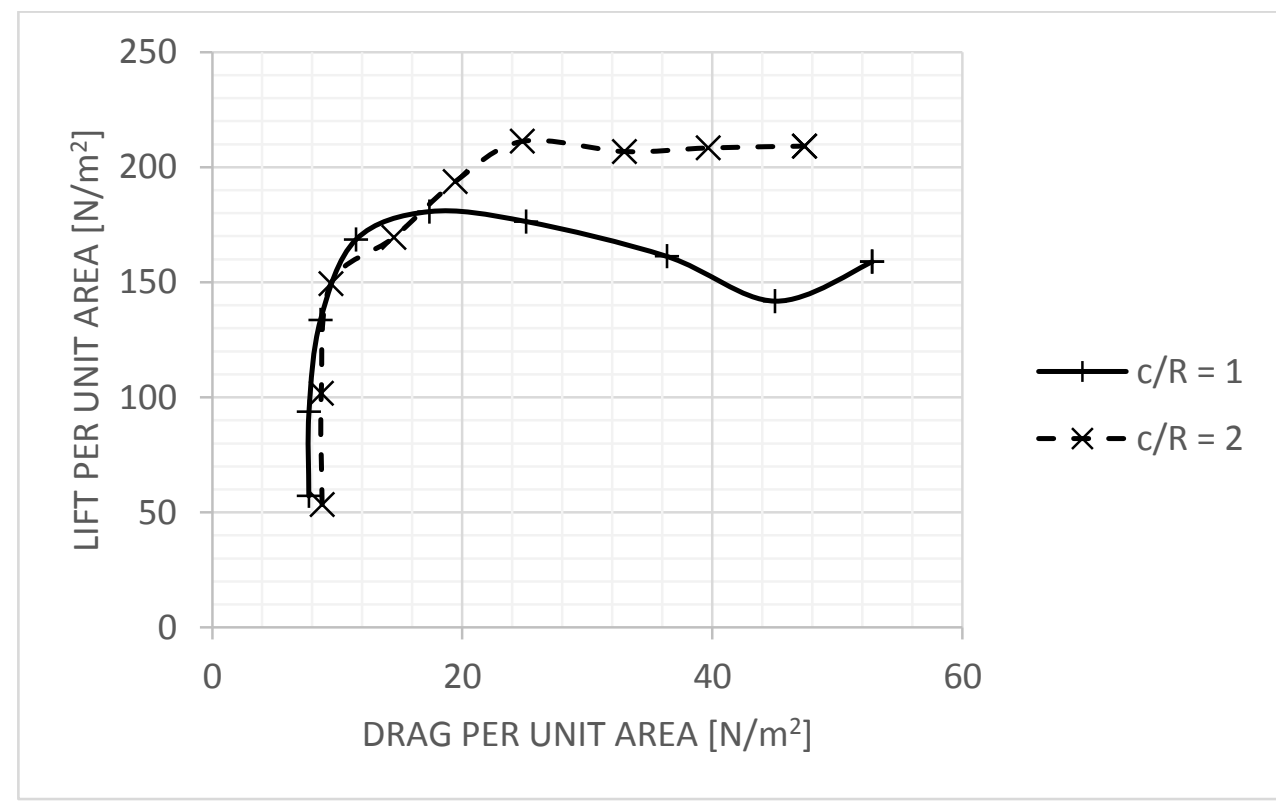

Fig. 11. Aerodynamic polar graphs for various ratios of wing cord to propeller radius, wingspan to propeller radius equal to 6 .

\section{Discussions}

Results in Figs. 10 and 11 show dependence of lift and drag unit forces for different configurations. It is clearly visible that decrease of wing area leads to lower drag in cruise 
condition. However, maximal lift per unit area is also considerably lower. This means that further optimization of the system is needed in order to meet both requirements, i.e. low energy consumption in cruise regime and low landing and take-off speeds.

From charts is also visible that optimum chord to propeller radius ratio for desired propeller is higher than two and lower than four, determined by comparison of L/D ratio.

Comparison of Figs. 10 and 11 shows that big influence to $\mathrm{L} / \mathrm{D}$ has ratio between "propeller density" - propeller diameter to wingspan, or ratio between affected and unaffected wingspan.

\section{Conclusion and future work}

CFD analysis of the wing-propeller interaction with special respect to distributed electrical propulsion is presented. Three different wing chords and two distances of the propellers are used. The results show potential of possible decrease of cruise drag and thus lower energy consumption. However, the system has to be optimized in order to meet all requirements, i.e. low take-off and landing speed and high cruise efficiency. Wind tunnel tests will be done for verification of the CFD computation.

This project is supported by the Grant Agency of the Czech Technical University in Prague, grant number: SGS19/054/OHK2/1T/12.

\section{References}

1. H.D. Kim, A.T. Perry, P. J. Ansell, AIAA 2018-4998 (2018)

2. X-57 Maxwell, Online [cit. 06.10.2019]: https://www.nasa.gov/specials/X57/index.html

3. Daher, Airbus and Safran team up to develop EcoPulse ${ }^{\mathrm{TM}}$, a distributed hybrid propulsion aircraft demonstrator, Online [cit. 06.10.2019]: https://www.daher.com/en/daher-airbus-and-safran-team-up-to-develop-ecopulse-adistributed-hybrid-propulsion-aircraft-demonstrator/

4. The Jet - Lilium, Online [cit. 06.10.2019]: https://lilium.com/the-jet

5. N.K. Borer et al., AIAA 2017-0209 (2017)

6. K.A. Deere et al., AIAA 2017-3923 (2017)

7. K.A. Deere et al., AIAA 2017-3925 (2017)

8. K.A. Deere et al., AIAA 2018-1275 (2018)

9. J.K. Viken, S.A. Viken, K.A. Deere, M.B. Carter, AIAA 2017-3922 (2017)

10. E.E. Larrabee, SAE Technical Paper 790585 (1979)

11. V. Běták, J. Fürst, Computational mechanics $2011,27^{\text {th }}$ conference with international participation, Pilsen, Czech republic 